\title{
Usage Of Chitosan-Silica with Crosslinking Agent As A Matrix For Slow Release Fertilizer
}

\author{
Raisza Tarida Savana, Dina Kartika Maharani* \\ Chemistry Department, Faculty of Mathematics and Natural Science \\ Universitas Negeri Surabaya \\ Surabaya, Indonesia \\ dinakartika@unesa.ac.id
}

\begin{abstract}
Research with the title of the use of silica chitosan with glutaraldehyde crosslinking agents as a matrix in the making of slow release urea fertilizer has been done. The purpose of this research was to determine the physical and chemical properties of slow release fertilizer coated with chitosan-silica matrix and also glutaraldehyde with a concentration of $1 \%, 1.5 \%$ and also $2 \%$ (v/v). Physical properties are known by SEM where it has been seen that the matrix has covered the fertilizer, for the chemical properties of slow release fertilizer can be analyzed from functional groups by FTIR to see the interaction between fertilizer, matrix and glutaraldehyde crosslinking agents. Slow release fertilizer has also been tested for nitrogen release levels. From the test, the composition of slow release urea fertilizer with chitosan-silica matrix and glutaraldehyde $1 \%(v / v)$ is more stable than the matrix with glutaraldehyde $1.5 \%$ and $2 \%(v / v)$.
\end{abstract}

Keywords- slow release fertilizer, chitosan-silica, glutaraldehyde

\section{INTRODUCTION}

Slow-release fertilizer, is a fertilizer that can slow the release of nutrient elements for plant growth. These elements are usually easily lost due to their solubility in high water, volatile, and denitrification processes occur in the fertilizer. One way to increase absorption efficiency and use of artificial nitrogen fertilizers (especially urea), among others, is by reducing the level of nitrogen fertilizer solubility by using a matrix to coat the fertilizer.

Materials that have the potential to make slow release fertilizer are chitosan. Chitosan is used as a fertilizer matrix to slow down because it can reduce production costs and make techniques that are environmentally friendly [1]. Chitosan can be used as a physical barrier to fertilizers which can reduce the rate of diffusion of water into core fertilizer and diffusion of nutrients beyond the core fertilizer [2]. Silica is widely used in slow release fertilizer because it has a small particle size, and is amorphous so that it affects the release mechanism of urea fertilizer which is more directed to the mechanism of the diffusion process [3]. Glutaraldehyde was commonly used as a crosslinking agent because glutaraldehyde increases the stability of chitosan by forming intermediate compounds.

The process of making slow-release fertilizer in this research was carried out by coating with materials that can protect nitrogen, namely chitosan-silica and also glutaraldehyde with glutaraldehyde concentrations $1 \%, 1.5 \%$ and $2 \%$. The slow release fertilizer that produced was incubated on the soil for a certain period of time to determine the nutrient release mechanism of fertilizer. Slow release fertilizer is characterized by FTIR to determine matrix functional groups with urea fertilizer. The surface morphology of the slow release fertilizer produced was characterized using SEM.

\section{MATERIALS AND METHOD}

\section{A. Materials}

A set of glassware, watch glass, measuring cup, drop pipette, hose, hot plate stirrer, magnetic stirrer, porcelain cup, analytical balance, oven, destructive pumpkin, electric stove, distillation device, mortar and pestle, titration tool, strainer 80 mesh, Scanning Electron Microscopy (SEM), Fourier Transform Infrared (FTIR). Urea fertilizer, TEOS (Merck), $\mathrm{CH}_{3} \mathrm{COOH}$ p.a (Merck), ethanol p.a (Merck), chitosan from shrimp skin purchased from CV. CHI MULTIGUNA, Indramayu, aquaeous and aqua demineralization, glutaraldehyde, tap water, soil, $\mathrm{HCl}$, kjeldhal tablet, $\mathrm{NaOH}$, $\mathrm{H} 2 \mathrm{SO} 4$, boiling stone, methyl red indicator, $\mathrm{Zn}$ plate.

\section{B. Method}

Urea fertilizer was mixed with chitosan-silica matrix, weight ratio $(\% \mathrm{w} / \mathrm{w})$ of urea fertilizer with a matrix of $7: 3$, stirred using a magnetic stirrer for 4 hours. Then dried. After drying the urea fertilizer coated with chitosan-silica matrix was soaked in glutaraldehyde $1 \%, 1.5 \%$ and $2 \%$ for 24 hours. Urea fertilizer cross-linked with chitosan-silica which has cross-linked with glutaraldehyde is then dried at room temperature until it is completely dry [4]. After obtaining urea fertilizer which has been coated with silica chitosan and cross-linked with glurataldehyde, it was tested using FTIR, SEM and nitrogen release test using kjeldahl method.

\section{RESULTS AND DISCUSSION}

\section{A. Nitrogen Release Level}

Nitrogen release testing was carried out on UF (urea fertilizer), CSUF (chitosan-silica urea fertilizer), CSGUF (chitosan-silica-glutaraldehyde urea fertilizer) 1\%, CSGUF $1.5 \%$ and CSGUF $2 \%$. The fertilizer is weighed as much as 1 gram mixed in 200 grams of soil. Soil that has been mixed with fertilizer added $100 \mathrm{~mL}$ of water for a period of 0 days, 7 days, 14 days, 21 days and 28 days. The washing water is collected and tested for nitrogen using spectrophotometer methods. Soil washing water was clear yellowish solution.

The soil washed water was tested for nitrogen content by taking $25 \mathrm{~mL}$ of soil washed water samples using the spectrophotometer method. Nitrogen content can be known from the absorbance obtained. The maximum absorption 
wavelength is obtained by reading the nitrogen containing solution at a wavelength of $410 \mathrm{~nm}$. The standard nitrogen curve was made using concentrations of $0.05,0.125,0.25$, $0.5,0.75,1,1.5$ and $2 \mathrm{ppm}$. The making is done with distilled water.

TABLE I. NITROGEN RELEASE PRECENTAGE DURING INCUBATION

\begin{tabular}{|c|c|c|c|c|c|}
\hline \multirow{2}{*}{ Days } & \multicolumn{5}{|c|}{ Precentage (\%) } \\
\cline { 2 - 6 } & UF & CSUF & $\begin{array}{c}\text { CSGUF } \\
1 \%\end{array}$ & $\begin{array}{c}\text { CSGUF } \\
1,5 \%\end{array}$ & $\begin{array}{c}\text { CSGUF } \\
2 \%\end{array}$ \\
\hline 0 & $0.93 \%$ & $0.67 \%$ & $0.79 \%$ & $0.69 \%$ & $0.90 \%$ \\
\hline 7 & $1.48 \%$ & $1.20 \%$ & $1.32 \%$ & $1.22 \%$ & $1.79 \%$ \\
\hline 14 & $4.76 \%$ & $4.06 \%$ & $4.06 \%$ & $5.94 \%$ & $9.66 \%$ \\
\hline 21 & $6.01 \%$ & $5.76 \%$ & $5.09 \%$ & $6.66 \%$ & $13.5 \%$ \\
\hline 28 & $7.24 \%$ & $5.97 \%$ & $6.07 \%$ & $7.36 \%$ & $17.13 \%$ \\
\hline
\end{tabular}
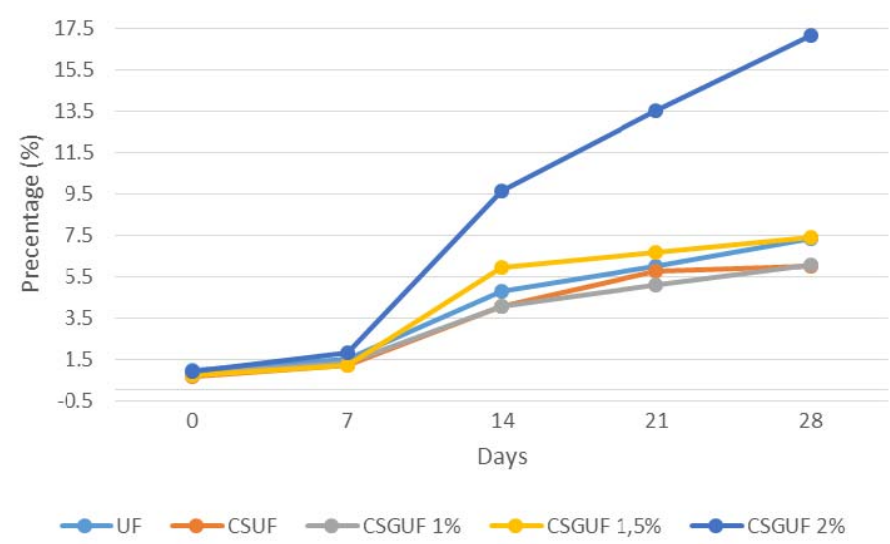

Fig.1. Chart of Nitrogen Release Level during Incubation

In the table of nitrogen levels released during incubation, there was an increase in the amount of nitrogen released over time. This increase in the amount of nitrogen slowly and controlled shows that nitrogen release occurs gradually. The level of nitrogen release in this study showed that the slow release fertilizer produced had a release standard in accordance with International Standard ISO / DIS 18644: 2016 , ie the initial nutrient release levels were less than $15 \%$ and nutrient release levels for 28 days were less than $75 \%$ as seen in Fig 1.

The precentage of $\mathrm{N}$ release in urea fertilizer with urea fertilizer which has been added with matrix is not far. Ureashaped granules such as those used in this study indicated that they have slow release properties due to their compressed form or more non-flour granules which slow down the release of nutrients, but generally the release of nitrogen in urea fertilizer is faster than slow release fertilizers made using chitosan-silica matrix-glutaraldehyde. This shows that the role of the matrix is able to inhibit nitrogen fertilizer release.

Water does not directly interact with fertilizer because there is a matrix that blocks, but water can penetrate the fertilizer core coated through the coating gap or in this case the chitosan-silica matrix-glutaraldehyde, after the water penetrates the fertilizer core there will be nutrient dissolution, which will cause formation inner pressure at the fertilizer core.

Fertilizer will experience swelling and cause the pore layer to become bigger. Nutrients are released through the pores of this layer diffusion which is driven by a concentration gradient in the layer, or through the flow of mass driven by a pressure gradient or flowing from high pressure to low pressure so that it can be said that the fertilizer release process does not occur simultaneously, but slowly because there is a matrix that blocks the release of these nutrients.

\section{B. IR Spectra}

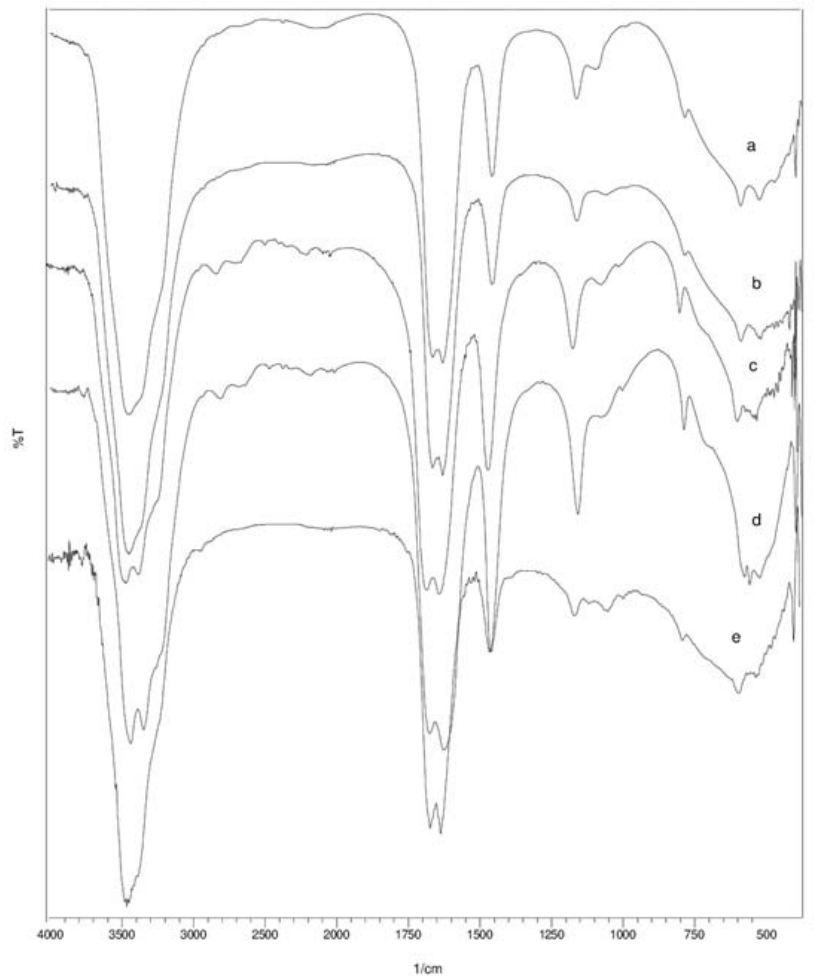

Fig. 2. FTIR spectra of urea fertilizer (a), silica fertilizer (b) chitosan fertilizer (c) chitosan-silica fertilizer (d) and chitosan-silica-glutaraldehyde fertilizer (e)

Based on FTIR spectra in Figure 2 it can be seen that urea fertilizer (a) has $\mathrm{NH}$ stretching bond at wave number $3450.77 \mathrm{~cm}^{-1}$ which indicates the presence of an amine group, besides that urea fertilizer also has $\mathrm{C}=\mathrm{O}$ stretching and $\mathrm{NH}$ bending at wave number 1664.62 and $1458.23 \mathrm{~cm}^{-1}$ so that it can be seen that urea fertilizer has amine groups, $\mathrm{C}$ $=\mathrm{O}$ stretching and $\mathrm{NH}$ bending.

In urea fertilizer which has been coated with chitosan matrix, there is a shift of wave number from $3450.77 \mathrm{~cm}-1$ to $3350.46 \mathrm{~cm}-1$ which indicates the interaction of urea and chitosan fertilizer. Urea fertilizer interaction with chitosan and silica matrix can be identified by a shift in wave numbers and changes in the intensity of urea fertilizer uptake in the wave number regions $3450.46 \mathrm{~cm}-1(\mathrm{NH}$ stretching) and $1664.65 \mathrm{~cm}-1(\mathrm{C}=\mathrm{O}$ stretching $)$ to 343726 $\mathrm{cm}-1$ and $1676.2 \mathrm{~cm}-1$ in urea fertilizer coated with chitosan-silica matrix.

Shifting of wave numbers in urea fertilizer and chitosansilica fertilizer showed an interaction between urea fertilizer and chitosan-silica matrix. Absorption in $1076.32 \mathrm{~cm}-1$ in chitosan-silica urea fertilizer showed Si-O-Si vibration absorption. Changes in intensity of wave intensity and a shift in wave numbers due to the interaction between $\mathrm{NH} 2$ groups in urea fertilizer with $\mathrm{OH}$ groups of chitosan and silica, so it can be concluded that the fertilizers coated with 
chitosan-silica matrix have amine groups, $\mathrm{C}=\mathrm{O}$ stretching and $\mathrm{NH}$ bending .

On the addition of glutaraldehyde to the fertilizer which has been coated with chitosan-silica matrix there is still $\mathrm{NH}$ functional group at wave number $3348.54 \mathrm{~cm}^{-1}$, but after adding glutaraldehyde there is no - $\mathrm{NH}$ functional group at the wavelength, which is amplified by the shift of wave number $3437.26 \mathrm{~cm}^{-1}$ became $3448.84 \mathrm{~cm}^{-1}$ in the functional group $\mathrm{O}-\mathrm{H}$. This is because - $\mathrm{NH}$ in chitosan has been covered by $\mathrm{OH}$ functional groups of glutaraldehyde. Addition of glutaraldehyde also causes a shift in the Si-O-Si wave number in the original wave number $1076.32 \mathrm{~cm}^{-1}$ to $1045.45 \mathrm{~cm}^{-1}$

\section{SEM Analysis}

SEM analysis has been done with the aim to determine the surface morphology of urea fertilizer and slow release fertilizer with the best release.

a)

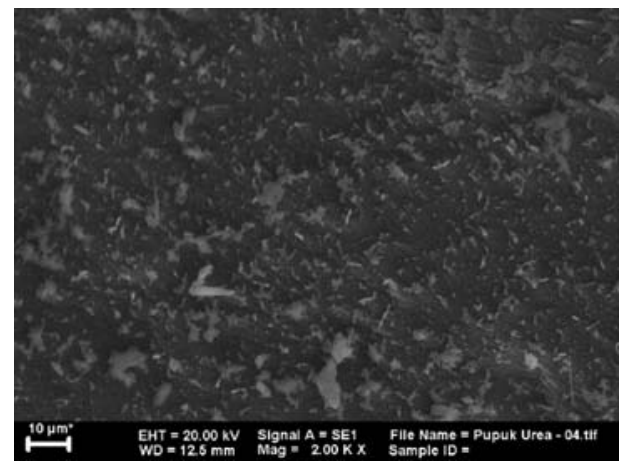

b)

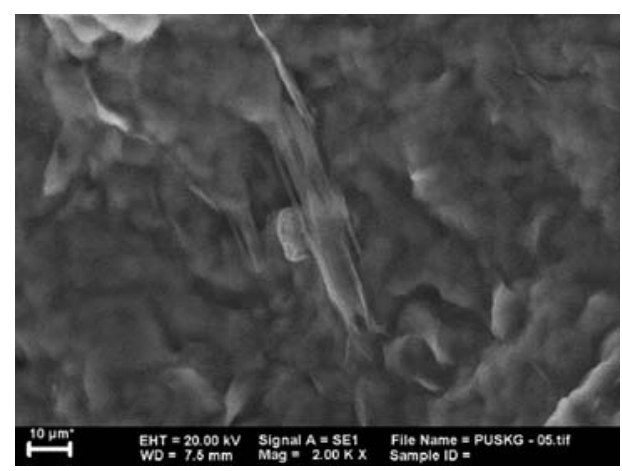

Fig. 3. Surface Morfology UF (a), and CSGUF 1\% (b)

From Figure 3 it can be seen surface morphology with magnification 2000X. In the picture (a) it can be seen that the surface urea fertilizer is initially irregular and unclear, after being coated with a matrix (b), there is a matrix attached. The results of this SEM indicate that urea fertilizer has a slow release function in which fertilizer cannot directly interact with water because urea fertilizer has been blocked by the matrix so that nitrogen fertilizer is not directly released when interacting with water.

\section{CONCLUSION}

Based on the results of data analysis it can be concluded that the composition of slow release urea fertilizer with the best chitosan-silica matrix and glutaraldehyde is a matrix with glutaraldehyde $1 \%(\mathrm{v} / \mathrm{v})$ because it is more stable in all aspects tested. this is also in accordance with International
Standard ISO / DIS 18644: 2016 (less than 15\% and 28 days of nutrient release levels less than $75 \%$ ).

\section{ACKNOWLEDGMENT}

Thank you to Prof. Dr. Suyatno, M.Si as chairman of the Chemistry Department of Universitas Negeri Surabaya and Prof. Dr. Suyono., M.Pd as dean of FMIPA Universitas Negeri Surabaya.

\section{REFERENCES}

[1]. L. Wu, M. Liu, and R. Liang. "Preparation and Properties of a Double-coated Slow-release NPK Compound Fertilizer with Superabsorbent and Water-retention". Bioresource Technology, 2008, vol.99: pp.547-554.

[2]. L. Wu, and M. Liu "Preparation and Properties of Chitosan-coated NPK Compound Fertilizer with Controlledrelease and Water-retention". Carbohydrate Polymers, 2008, vol.72 : pp. 240-247.

[3]. D.Swantomo, R. Rochmadi, K.T. Basuki., and R. Sudiyo. "Effect of Silica Fillers on Characterization of Cellulose-Acrylamide Hydrogels Matrices as Controlled Release Agents for Urea Fertilizers". Indo. J. Chem, 2014, Vol. 14 (2): pp.116-121.

[4]. L.F.E Wulan and D.K Maharani. "Usage of ChitosanSilika as a Matrix for Slow Releasae Fertilizer" (Pemanfaatan Kitosan-Silika sebagai Matriks pada Pembuatan Pupuk Urea Slow Release). UNESA Journal of Chemistry, 2017, Vol 6 (1): hal 73-75 Vol. 10 No. 3396. 